Trabalhar Cansa. Cesare Pavese. Tradução de Maurício Santana Dias. (São Paulo: Cosac Naify / 7Letras, 2009.)

\title{
O CAMINHO SOLITÁRIO E A INTENSA REFLEXÃO: Trabalhar cansa, de Pavese
}

Trabalhar cansa (Lavorare Stanca, 1935) chega ao mercado brasileiro numa parceria das editoras Cosac Naify e 7Letras, com tradução de Maurício Santana Dias. É o primeiro livro do poeta e escritor Cesare Pavese, considerado uma das grandes vozes italianas no período entre as duas guerras mundiais. As obras de Pavese traduzidas no Brasil são: O belo verão (1987, pela Brasiliense), A lua e as fogueiras (1988, pelo Círculo do Llivro, e 2003 pela Berlendis\&Vertecchia), Oficio de viver (1988, pela Bertrand Brasil), Mulheres só (1988, pela Brasiliense) e Diálogos com Leucó (2001, pela Cosac Naify).

Pavese faz parte do panorama da literatura italiana do século $\mathrm{XX}$, não só como poeta, mas também como escritor de romances e contos e tradutor. Nessa lista não é possível esquecer da sua participação na famosa equipe, composta também por Elio Vittorini, Italo Calvino e Natalia Ginzburg, que atuou ativamente no mercado editorial italiano por meio do trabalho na Editora Einaudi.

Apesar de seu distanciamento da política, faz parte do grupo de intelectuais antifascistas piemonteses, formado por Giulio Einaudi, Massimo Mila, Leone Ginzburg, Giulio Carlo Argan, Norberto Bobbio. Tal grupo é lembrado pelo crítico literário Giuseppe Petrônio como o "fior fiore dell'antifascismo liberalsocialista". Como Leone Ginzburg e tantos outros, Pavese também passa pela experiência do cárcere durante o fascismo, um período de reclusão na Calábria que lhe proporciona um contato maior com a literatura (fruto desse momento é o breve romance Il carcere) e inicia o seu diário, Oficio de viver, que o acompanhará até o trágico suicídio em 1950.

De retorno a Turim, Pavese continua o trabalho iniciado nos anos anteriores de tradução de autores americanos e ingleses. Alguns dos autores traduzidos são Sinclair Lewis, Herman Melville, Sherwood Anderson, James Joyce, John dos Passos, John Steinbeck, Willian Faulkner, Daniel Defoe, Charles Dickens. Como se vê, há uma imersão na literatura americana, principalmente a daqueles anos. Seguindo o título de um texto de Calvino "Traduzir é a verdadeira forma de se conhecer um texto", Pavese adentra, apesar de nunca ter-se deslocado para o outro continente, no diversifica- 
do universo dos EUA. Um mundo, "o outro", que vai sendo descoberto a partir das viagens literárias mediadas pela leitura e depois pelo trabalho de tradução. Em um artigo publicado no jornal L'Unità, de 20 de maio de 1945, dirá Pavese:

Nos nossos esforços para compreender e para viver sorriram para nós vozes estrangeiras: cada um de nós buscou e amou a literatura de um povo, de uma sociedade distante, e falou dela, a traduziu, fez dela a pátria ideal. Tudo isso na linguagem fascista chamava-se esterofilia [...] Naturalmente não podiam admitir que estávamos procurando na América, na Rússia, na China, e quem sabe onde, um calor humano que a Itália oficial não nos dava. Menos ainda que estávamos procurando simplesmente nós mesmos. Na verdade foi assim mesmo. Lá embaixo nós procuramos e encontramos nós mesmos. Das páginas bizarras daqueles romances, das imagens daqueles filmes veio a primeira certeza, a de que a desordem, o estado violento, a nossa inquietação e a de toda a sociedade que estava ao redor, podiam ser resolvidos e apaziguados num estilo, numa ordem nova e deviam transfigurar numa nova lenda do homem.

Com efeito, é uma descoberta que aos poucos se revela e conduz o olhar pavesiano para além dos traços americanos. É, na verdade, lendo e relendo, decodificando e recodificando com a atividade tradutória, que o poeta de Santo Stefano Belbo passa a ver de uma outra perspectiva o contexto piemontês e italiano no qual estava inserido. A ligação com a própria terra de origem é para Cesare Pavese não só afeto e memória, mas é essa relação que alimenta o espírito do poeta e apresenta-se como um dos temas mais recorrentes em seus textos. É, portanto, a partir da leitura do outro que Pavese (re)define o seu foco: as colinas, as Langas, os dias de ócio, o rio Pó, camponeses, proletários; questôes que estão também condensadas no binômio campo X cidade. Imagens que podem ser identificadas em todo o seu percurso e, consequentemente, na sua produção literária. Nesse livro de estreia, Trabalhar can$s a$, por exemplo, elas permeiam todos os poemas.

A edição brasileira é baseada na segunda edição da obra datada de 1943, publicada pela editora Einaudi. É composta por uma apresentação de Maurício Santana Dias, pelos 70 poemas que formam o livro e um apêndice com dois textos assinados por Pavese: "O ofício de poeta" e "A propósito de alguns poemas ainda não escritos". Nessa mesma edição de 1943, é possível identificar pequenas mudanças e acréscimos em relação à primeira, como aponta Maurício Santana Dias no texto de introdução. Pavese acompanha de forma ativa esse processo de reedição: insere poemas antes censu- 
rados pelo regime e outros inéditos, altera algumas pontuações, faz pequenas modificaçooes e, ainda, acrescenta dois textos de reflexão sobre a temática, a forma, a métrica das poesias ali contidas.

A apresentação de Maurício Santana Dias dá um panorama bastante detalhado da vida e da atividade de Cesare Pavese, pouco conhecida no Brasil, mas em alguns momentos, quando trata das poesias, pode parecer para o leitor comum um pouco técnica. Os 70 poemas do livro são agrupados em seis seções: Antepassados (Antenati), Depois (Dopo), Cidade no campo (Città in campagna), Maternidade (Maternità), Lenha verde (Legna verde), Paternidade (Paternità).

A primeira, Antepassados, é formada por 11 poemas e as imagens presentes nestas poesias serão o símbolo da narrativa pavesiana: o retorno à região geográfica das Langas, a infância - um momento feliz da vida -, o silêncio e a não comunicação. Temas que podem ser mais tarde realocados nos binômios campo x cidade e infância $\mathrm{x}$ vida adulta. Esta seção é aberta com o paradigmático poema "I mari del Sud”. Na segunda seção, Depois, o leitor encontra 15 poesias que, como definiu Calvino, apresentam um "motivo amoroso e sensual num tom de contemplação e melancolia" - pode-se pensar aqui nas complicadas relações e decepçôes amorosas de Pavese. Os títulos de algumas poesias dessa seção são: "Agonia", "Mulheres apaixonadas", "Mania de solidão" e "A puta camponesa". A terceira seção, Cidade no campo, é aquela com mais poemas, no total 19, e parece ser a mais "empenhada" de todo o livro. Os personagens principais são o camponês e o operário que, mesmo em ambientes diferentes, trabalham duro e fadigam. "O cansaço do dia os empurra pro sono/ e as pernas estão destroçadas. Alguns só imaginam/ e comer sonolentos, quem sabe sonhando" são alguns versos de "Crepúsculo de areeiros". Esta parte se conclui com a poesia que dá título ao livro "Trabalhar Cansa”, iniciando com a oposição já mencionada infância $\mathrm{x}$ vida adulta: "Travessar uma rua fugindo de casa/ só um menino o faria, mas este homem que passa/ todo o dia nas ruas não é mais menino/ e não foge de casa”. Maternidade é a quarta seção e tem 10 poesias. Aqui a imagem da mulher retorna, mas não mais como algo sensual e sim como a provedora, quer dizer, o símbolo de fertilidade. A quinta seção, Lenha verde, apresenta 7 composições, e é possível observar que há o predomínio da temática social e política como, por exemplo, nos versos contidos em "Geração": "Numa tarde de luzes distantes ouviram-se tiros/ na cidade, e acima do vento, medonho,/um clamor descontínuo. 
Calaram-se todos/ [...] há operários calados e alguns estão mortos". A sexta e última seção, Paternidade, é composta por 8 poesias e se contrapõe pelo próprio nome à seção Maternidade. Aqui são privilegiados os temas relacionados à solidão e à incomunicabilidade. "Fala pouco o amigo, e esse pouco é estranho" é o primeiro verso de "Mediterrânea", poesia que abre essa parte.

A tradução de Maurício Santana Dias tem escolhas bem precisas. Professor de literatura italiana da USP, ele vem cada vez mais se destacando como um importante elo de ligação entre Brasil e Itália. $\mathrm{O}$ trabalho tradutório pode ser concebido aqui como um diálogo de múltiplas faces que proporciona, haja vista a própria experiência pavesiana, uma série de relações entre os dois sistemas literários envolvidos. Na parte "Traduzir Trabalhar cansa", Santana Dias oferece ao leitor algumas motivações de suas escolhas:

Antes de finalizar este estudo, é necessário examinar a constituição formal dos poemas de Lavorare Stanca e, por conseguinte, explicitar as minhas próprias opçōes de tradução. A tarefa deve começar obviamente pala análise de "I mari del Sud", o primeiro e mais longo poema do livro, aquele que estabeleceu o padrão pelo qual Pavese se guiaria durante a década de 1930 e 1940 . Porém, antes de passar à leitura dos textos, cabe reiterar que todas as composiçōes do livro se originam a partir de um verso básico: o verso quantitativo de ritmo anapéstico, constituído de uma unidade mínima formada por duas sílabas breves e uma longa. Não por acaso, o anapesto é o verso que inicia o livro e lhe dá a cadência" (p. 54-55)

Ao iniciar com esse fragmento a reflexão sobre o processo tradutório, é possível identificar uma opção inicial que norteará todo o trabalho de tradução das 70 poesias: a preferência e o privilégio dado à métrica. É como se o olhar do tradutor fosse quase sugado pelos elementos formais - a matriz rítmica e a linguagem - e pelo tom monocórdio pavesiano. Tal predileção também fica clara nas mais de dez páginas dedicadas a essa questão na apresentação. Para finalizar, Maurício Santana Dias cita traduções de Lavorare stanca em outras línguas (a francesa Travailler fatigue, de Gilles de Van; a inglesa Hard labour, de William Arrowsmith; a catalã Trabalhar cansa, de J.M. Miñoz Pujol; a portuguesa Trabalhar cansa, de Carlos Leite) e algumas antologias que incluem essa obra de Pavese. Todas essas traduções citadas e consultadas têm uma escolha diferente, como pontua o tradutor, elas não mantiveram na "língua de chegada a métrica e o ritmo de Pavese: seus poemas foram vertidos quase sempre em versos livres e não raro tornados mais líricos e melodiosos do que de fato o são" (p. 72-74). 
Tanto já se discutiu e se vem debatendo sobre os inúmeros e complexos aspectos, positivos e negativos, que envolvem o processo tradutório. Ora, fazer uma tradução significa também fazer escolhas e, por sua vez, escolher comporta sempre, de alguma forma, ganhos e perdas. O último parágrafo de Santana Dias aponta o que para ele seriam as perdas dessas traduções consultadas:

Pelo que foi exposto, pode-se deduzir que traduçōes dessa natureza não sejam as mais adequadas aos poemas em questão. Afinal, o próprio Pavese havia rejeitado o verso livre por considerá-lo impróprio à sua poesia, ou seja: "Pela desordenada e caprichosa abundância que ele costuma solicitar à fantasia." Desse modo, uma tradução em versos livres - ou que simplesmente não acompanhe de perto o ritmo sempre igual e monótono dos versos pavesianos -, por mais feliz que seja, terá perdido de vista o projeto do autor, ou seja, o ato mais radical e característico do poeta piemontês: a busca incessante de "apreender o real", de dar uma forma e um sentido próprios a um mundo que em última instância lhe pareceu alheio. (p. 73)

O privilégio dado à métrica, que é sem dúvida um ganho da tradução brasileira, pode provocar certas perdas. Alguns pequenos exemplos estão na primeira poesia "Os mares do Sul":

mi ha detto “...ma hai ragione. La vita va vissuta lontano dal paese: si profetta e si gode

Disse ele, “...tens razão. A vida só é vivida

Distante de sua casa: se aproveita e se goza (p. 78-79, grifo nosso)

E mais adiante

Mio Cugino ha una faccia recisa. Comprò un pianterreno nel paese e ci fece riuscire un garage di cemento con dinazi fiammate la pila per dar la benzina e sul ponte ben grossa alla curva una targa-réclame. Poi ci mise un meccanico dentro a ricevere i soldi e lui girò tutte le Langhe fumando

S'era intanto sposato, in paese. Pigliò una ragazza

Ele tem uma cara obstinada. Comprou um terreno na aldeia e ergueu uma sólida garagem

que ostentava, brilhante, uma bomba para a gasolina e, na ponte, bem grande, na curva, um cartaz chamativo.

Contratou um mecânico que recebia o dinheiro e foi passear nas Langas, fumando.

Entretanto casara, na aldeia. Pegou uma garota (p. 78-79, grifo nosso) 
Nesses trechos, um elemento que chama a atenção é a palavra italiana paese, traduzida, na mesma poesia, com dois significados diferentes: o primeiro casa, no sentido figurado de lar e de tudo o que é familiar, e o segundo denotativo que é realmente aldeia, vilarejo. Uma situação análoga também acontece com o vocábulo em português serena, que nesta mesma poesia é traduzido com o seu correspondente serena - notti serenel noites serenas, mas em "Agonia”, sétimo poema da seção Depois, aparece serena como correspondente do vocábulo italiano stessa, cujo significado seria mesma: ogni volto che passa e restare la stessal cada rosto que passa e manter-me serena (p.138-139).

Ainda, recuperando os outros grifos do segundo fragmento acima, há um equívoco na tradução da palavra pianterreno. Na língua italiana também existe a palavra terreno que é escrita e tem o mesmo significado que em português. Todavia, a palavra escolhida por Pavese, pianterreno, possui um outro signifcado, isto é, andar térreo. O que interfere, consequentemente, na continuação do verso seguinte. De fato, não é necessário erguer ou construir uma garagem, na verdade, um espaço que já existia e localizava-se no andar térreo foi transformado em uma garagem. Essa transformação fica clara na expressão "ci fece riuscire".

Um outro aspecto que é importante lembrar consiste nas referências poéticas de Cesare Pavese. Todo o percurso do poeta é marcado pela leitura e estudo de alguns clássicos como Leaves of Grass de Walt Whitman, Les fleurs du Mal de Charles Baudelaire e a Ilíada de Homero - é bom lembrar que o próprio Pavese organizou e prefaciou uma edição dessa obra. Trabalhar cansa, portanto, apresenta-se como uma obra de exploração, mas não experimental, que pode ser vista e lida a partir de três momentos. O primeiro é caracterizado por aspectos da cultura e literatura americana, como já dito, fruto da atividade de tradução, principalmente em relação às paisagens e à redescoberta do Piemonte, terra natal de Pavese. No segundo momento, as imagens, sempre presentes, recebem um novo tratamento e são incorporadas à narrativa; para tal Pavese cria um sistema de analogias. Enfim, o terceiro momento é assinalado por uma espécie de imersão na subjetividade. Tais questôes são colocadas e discutidas nos dois textos contidos no apêndice.

A produção de Cesare Pavese, marcada pela disciplina, reflexão e estudo, pode ser vista como uma terceira via diante do contexto literário e cultural promovido pelo fascismo de um lado e o 
grupo da poesia hermética do outro. O poema-narrativo escolhido pelo autor, que recusa o verso-livre como é colocado nos textos finais, é a marca pavesiana dos poemas iniciais. O que se apresenta é uma poesia caracterizada por um estilo límpido e coloquial. Aspecto que algumas vezes não foi muito bem compreendido pela crítica literária, que só (re)conhecia Pavese pelas traduçōes feitas que não estavam de acordo com a linha determinada pela cultura oficial fascista. Escritor, poeta, tradutor, diretor de uma editora: são esses os perfis que vão se delineando ao longo do seu solitário percurso. Trabalhar cansa é um conjunto, fruto de um intenso processo de reflexão intelectual, que expressa o rigor, a dedicação e a fadiga do poeta diante do trabalho com a palavra.

Patricia Peterle 